\title{
A constituição da subjetividade docente no Brasil: um contexto global
}

\author{
The constitution of teacher subjectivity in Brazil: some global context
}

\author{
Stephen J. Ball, Patrick Bailey, \\ Paula Mena, Pablo Del Monte, Diego Santori, \\ Chun-ying Tseng, Helen Young, Antonio Olmedo \\ Universidade de Londres
}

\section{Resumo}

Este artigo explora aspectos das reformas educacionais que estão ocorrendo no Brasil, relacionando-os com uma 'visão global' que se aproxima das tendências e semelhanças que podem ser encontradas nas reformas educativas neoliberais em todo o mundo. Nós vamos delinear inúmeros processos inter-relacionados que se fazem presentes na escola como um local de trabalho, incluindo a intensificação do trabalho docente, a flexibilização da força de trabalho no ensino e a liberação da oferta de serviços na educação pública. $\bigcirc$ que será mostrado é que esses processos tem sido determinados por políticas neoliberais em escala global, por intermédio de uma combinação de privatizações endógenas e exógenas. As reformas que ocorrem no Brasil, e em muitos lugares, agem poderosamente não somente sobre as práticas e os valores da educação pública, mas também sobre as relações sociais no interior da escola e no entorno e para além do escolar. Elas tem um impacto significativo sobre o profissionalismo docente e opera para constituir docentes e suas subjetividades como performance e competição. Embora enfatizemos tendências gerais das reformas educativas neoliberais, também assistimos a algumas políticas locais específicas em inúmeros países.

Palavras-chave: Reforma educacional. Neoliberalismo. Performatividade. Trabalho docente.

\section{Abstract}

This paper explores some of the educational reforms which are taking place in Brazil and sets these within a 'global overview' which pays close attention to the trends and commonalities which can be seen in neoliberal education reforms around the world. We will outline a number of interrelated processes that are acting on the school as a workplace, including intensification of teachers' work, flexibilisation of the teaching workforce, and the liberalisation of the supply side of public education. What will be shown is that these processes are being informed by neoliberal policy enactments on a global scale through a combination of endogenous and exogenous privatisations. The reforms taking place in Brazil, and elsewhere, act powerfully not only on the practices and values of public education, but also on the social relationships within the school and supra-school environment. They have a significant impact on teacher professionalism and work to constitute teachers and their subjectivity in line with performance and competition. Although we highlight general trends in neoliberal educational reforms, we also attend to some of the local specificities of policy enactments in a number of different countries.

Keywords: Educational reform. Neoliberalism. Performativity. Teachers'work. 


\section{Introdução}

A expansão do movimento de reestruturação econômica global nas três últimas décadas tem produzido notáveis desenvolvimentos similares por todo o mundo. Em particular, este processo de transformação tem modificado drasticamente como pensamos e concebemos a natureza da escolarização. Além disso, tem resultado em uma profunda mudança no modo como conceptualizamos profissionalismo docente. Docentes são mobilizados a atender objetivos políticos a fim de alcançar um desempenho educativo e, a longo prazo, favorecer o crescimento econômico e reforçar a competitividade global. A redefinição do profissionalismo docente paripassu com as reformas educacionais contemporâneas delimita espaço para os docentes como seres autônomos; de modo mais significativo, produz novos docentes que internalizam as exigências da performatividade e, assim, tornam-se auto-regulados e "autônomos" em uma nova sensibilidade.

Alguns aspectos desta dupla reestruturação - autonomia e performatividade - são evidentes no Brasil. Em meados dos anos 90, durante a administração de Fernando Henrique Cardoso, o sistema educacional foi

10 reformado com a introdução de uma agenda política que teve impactos significativos sobre a vida docente, estudantil e, por isso, sobre a sociedade brasileira. Com a nova lei de educação (Lei de Diretrizes e Bases da Educação Nacional - LDB), promulgada em 1996, e outros instrumentos, inicia-se um processo de descentralização que traz consigo novas formas de governança: ao mesmo tempo em que estados e municípios tornam-se responsáveis pela administração e oferta da educação, nos diferentes níveis, as escolas, como unidades, são chamadas a se tornarem mais autônomas em seu funcionamento. Entretanto, o estado central (União) manteve a avaliação como sua responsabilidade, assim como a produção de relatórios sobre a oferta da educação, ambos servindo como tecnologias de controle e recentralização.

Simultaneamente, o currículo tem sido modificado com a introdução de novas abordagens - currículo baseado em competências - acompanhando as orientações de Agências Internacionais, tais como Banco Mundial, Organização para a Cooperação e Desenvolvimento Econômico (OCDE), Banco Inter-americano de Desenvolvimento (BID) etc. Nesse sentido, a reforma no Brasil e em inúmeros países deve ser considerada no contexto de expansão de um discurso político mais amplo que promove uma educação funcional para 
as demandas da chamada "economia global". Os dispositivos políticos e os componentes ideológicos incorporados nesse discurso agem poderosamente tanto na definição do currículo como nas identidades docentes e em sua constituição como profissionais. Isso ocorre porque mesmo que descentralização e autonomia sejam duas peças chave na reformulação da oferta educacional, o funcionamento da reforma também incorpora medidas que restringem a autonomia e o profissionalismo docente.

Mesmo que os governos mais recentes tenham afirmado uma maior presença e uma responsabilidade mais ativa do estado central (União) na oferta da educação e de condições de trabalho mais decentes para o magistério, os caminhos do que é conhecido como tendências neoliberais podem ser encontrados em uma complexidade de redes, ideologias e eventos interconectados. Esta é a razão pela qual é importante reconhecer que reformas e resistências, operando em vários níveis, podem ser interpretadas como respostas ativas para o conjunto de concepções e práticas neoliberais que impactam os docentes em todo o mundo. De fato, é importante observar que as ações coletivas de resistência tem sido significativas no Brasil (p.ex., no caso do Piso Nacional de Salário), assim como em outros lugares, tal como no Chile, de acordo com cada condição local.

Educação é uma arena de lutas políticas em que a contestação de uma política no nível micro ou macro pode redefinir o curso das políticas no futuro. (LARNER, 2000).

Este artigo apresenta alguns aspectos desse contexto global para buscar um entendimento mais amplo a respeito dos processos que estão ocorrendo no Brasil. Iniciamos descrevendo alguns mecanismos típicos do conjunto das políticas neoliberais que podem ser encontrados nas reformas educacionais em todo o mundo, para depois argumentar que esses componentes políticos, e em seu conjunto mais amplo, como discursos políticos, funcionam para reconstituir as subjetividades docentes. Não obstante, identificamos e isolamos tendências gerais, efeitos e similaridades dentre as reformas neoliberais, o que não expressa uma compreensão monolítica e singular de tais processos. Nesse sentido, ressaltamos a importância de uma atenção para os contextos nacional, regional e local, nos quais tais reformas ocorrem. Concordamos com a avaliação de Springer (2010, p. 1031 ) de que o "Neoliberalismo é apropriadamente compreendido tanto como uma prática política, social e cultural, 
baseada na especificidade local, como uma racionalidade econômica globalmente informada."

\section{Neoliberalismo e reformas educativas}

Um dos mais penetrantes e consistentes argumentos subjacentes às reformas educativas contemporâneas é a assertiva de que a mão invisível do mercado inexoravelmente produzirá escolas melhores. (APPLE, 2004). Esta ideia é expressão do que geralmente é referido como neoliberalismo, um conjunto de noções e práticas de governança que estendem o modelo das relações de mercado para áreas anteriormente reguladas por outras racionalidades. (LARNER, 2000). Neste novo quadro de mercado, as escolas tornam-se mais suscetíveis a medidas externas baseadas em resultados e mais receptivas aos desejos dos consumidores. Assim, uma ênfase maior é dada à gestão baseada na opinião pública, a qual inclui o aumento dos testes nacionais e da inspeção escolar, a fim de atrair consumidores e maximizar o rendimento. Escolas são tornadas unidades de negócios que competem umas com as outras

12 "[...] para assegurar que acolham uma população (estudantes) considerada mais provável para um bom desempenho em relação a medidas externas." (BALL; YOUDELL, 2007, p. 44). Em outras palavras, há uma expectativa de que as escolas operem "[...] mais como empresas privadas, para se introduzirem no mercado, para competirem uma com a outra por estudantes e por mais recursos." (SMYTH, 1996, p. 39).

Deve ser brevemente mencionado que a ação das organizações internacionais na introdução das mudanças educacionais no Brasil tem sido crucial no delineamento dessas reformas em educação a partir de uma orientação neoliberal. A mesma situação tem sido observada em outros países latino-americanos no mesmo período histórico. (GENTILI; SUAREZ; STUBRIN; GINDIN; 2004). Organizações internacionais multilaterais, tais como CEPAS, UNESCO e o Banco Mundial têm definido uma série de orientações como narrativas que requerem: a existência de uma nova ordem globalizada com novas formas de produção às quais os sistemas de educação devem se adaptar; que a educação seja funcional no fornecimento de força de trabalho qualificada e na contenção da pobreza; a descentralização e autonomia institucional como forma de se obter uma oferta mais eficiente de educação. ISILVA; ABREU, 
2008). Ademais, no que se refere à carreira e formação docente, Myriam Feldfeber (2007, p. 446) identifica alguns desses dispositivos neoliberais importados nas reformas educativas na América Latina: "[...] redefinição da carreira docente por meio da flexibilização do trabalho, salário baseado no mérito, incentivos baseados no desempenho, incentivos para atrair 'o melhor' para a profissão, avaliações baseadas em 'regras objetivas', mecanismos de certificação e definição de padrões em nível nacional e internacional."

Sem dúvida, há muitas formas por meio das quais o trabalho docente está sendo remodelado. Essas formas incluem os termos e condições de contratação do corpo docente, e os modos como são formados, avaliados e representados. Há muitos e diferentes elementos nesse processo, os quais considerados em conjunto agem para corroer a autonomia profissional e a autoridade docente, ao mesmo tempo em que abrem espaço para a emergência da competição, para setores privados e para a busca de lucro em educação como algo possível, e mesmo necessário. $\bigcirc$ que será mostrado aqui é que isso está sendo obtido por meio de uma combinação de formas de privatização, endógena e exógena, como parte de um fenômeno global. A fim de entender as várias formas pelas quais o profissionalismo docente está sendo enfraquecido, esboçaremos processos variados e inter-relacionados que agem na escola como local de trabalho, incluindo a intensificação do trabalho docente, a flexibilização da força de trabalho no ensino e a liberalização dos serviços da educação pública. Antes, porém, a privatização endógena será apresentada e explicada em relação ao crescimento da Nova Gestão Pública na educação pública.

\section{Privatização endógena}

Nova Gestão Pública (NGP)

Docentes e seu trabalho são cada vez mais objeto de regulação, intervenção e prescrição. Isso é reconhecido, em parte, por uma carga política de desconfiança sobre os docentes e por uma ortodoxia política da nova direita/ neo-conservadora que, embora não onipresente, é internacionalmente proeminente. (APPLE, 2001). Uma gestão performática (baseada no desempenho) e sistemas de prestação de contas e responsabilização (accountability) têm colonizado os sistemas educacionais em todo o mundo. Um processo que pode 
ser personificado na figura do "gestor" e que está alimentado pelos discursos e práticas do que algumas vezes é denominado Nova Gestão Pública (NGP). A proliferação da NGP em educação é um exemplo primoroso da privatização endógena, a qual "[...] envolve a importação de idéias, técnicas e práticas do setor privado a fim de tornar o setor público mais mercadológico e mais parecido com as empresas." (BALL; YOUDELL, 2008, p. 14).

De forma mais significativa, a NGP funciona, ao lado das políticas centralizadas, como um princípio organizacional e operacional. Nesse sentido, a NGP cria as condições para o desenvolvimento de uma cultura da performatividade nas escolas, "[...] um regime de responsabilização que emprega julgamentos, comparações e mostras de 'qualidade', ou momentos de 'promoção' ou inspeção." (BALL, 2008, p. 49). Por meio desse regime, o trabalho docente e as relações que estabelece com funcionários e estudantes ficam reduzidas a uma contabilidade ligada diretamente aos requisitos do mercado de indicadores de competição e desempenho (performance). A celebração da gestão ou 'funções diretivas' nas escolas, como oposição aos docentes, é uma parte muito simbólica desse processo. 'Funções diretivas' são crescentemente fortalecidas com um número maior de responsabilidades, com

14 formas variadas, que podem ser vistas como figuras-chave nas reformas neoliberais e na 'modernização' do setor público. Elas "[...] desempenham uma função-chave no desgaste dos regimes ético-profissionais nas escolas e na sua substituição pelos regimes empresariais-competitivos - um processo de 'desprofissionalização' [docente]." (BALL, 2008, p. 47).

A aplicação e a execução da NGP em países 'emergentes e em desenvolvimento', no mundo, podem ser vistas em iniciativas como a 'Educação para Todos', liderada pela UNESCO. $\bigcirc$ 'movimento' descreve a si mesmo com um 'compromisso global para prover educação básica de qualidade para todas as crianças, jovens e adultos... Como agência líder, a UNESCO foca suas atividades em cinco áreas-chave: diálogo político, acompanhamento, advocacia, mobilização de financiamento e desenvolvimento de capacidade' (UNESCO). Essas 'cinco áreas-chave' na prática envolvem a importação de tecnologias performáticas via aplicação de políticas gerais delineadas para impor sistemas de responsabilização/prestação de contas e de gestão performática nas escolas. Sem dúvida, um dos seis objetivos esboçados pela UNESCO é 'melhorar todos os aspectos da qualidade da educação e garantir a excelência para todos, para que resultados de aprendizagem reconhecidos 
e mensuráveis sejam alcançados por todos, especialmente em alfabetização, matemática e habilidades essenciais para a vida' (UNESCO). A redução da educação a resultados mensuráveis nesse sentido, como mostrado acima, é um elemento chave da NGP e, como veremos, realimenta o docente, sua subjetividade e seu trabalho.

Reprofissionalização e desprofissionalização

Nesse processo endógeno, e por meio dele, há uma inserção de novas sensibilidades, práticas e formas de subjetividade nas escolas, um processo dual de 'reprofissionalização' e 'desprofissionalização'. Reprofissionalização talvez seja melhor compreendido como uma mudança de ênfase, que se distancia das capacidades profissionais docentes, em direção a capacidades transformacionais dos líderes individuais e gestores do setor público. Ao mesmo tempo, docentes são desprofissionalizados com a perda de autonomia para a tomada de decisões, por um deslocamento do julgamento para o critério de medida, por um maior controle e vigilância sobre o seu trabalho, e por um currículo cada vez mais prescritivo e com metas de desempenho centralizadas.

A intensificação do trabalho docente também contribui para a erosão da autonomia e da autoridade profissional. Está diretamente ligada ao aumento do gerencialismo e da performatividade. Larson (1980, p. 166-167) vê a intensificação como "[...] um dos modos mais tangíveis em que privilégios laborais de trabalhadores educados são corroídos [... ]" e contribui para o que Hargreaves (1994, p. 118 ) descreve com um estado individual e institucional de "[...] sobrecarga crônica e persistente, que reduz áreas de discernimento pessoal, inibe o envolvimento e o controle sobre o planejamento de longo prazo, e promove a dependência de especialistas e de materiais produzidos externamente."

Apple observa que "[...] tanto diretores quanto docentes vivenciam cargas de trabalho pesadas e demandas sempre crescentes de prestação de contas $[. .$.$] ", e acrescenta que "[...] esses movimentos são verdadeiramente$ globais. Suas lógicas têm se espalhado rapidamente para muitas nações." A intensificação também pode ser vista como um sintoma da 'proletarização' docente (APPLE, 1982; 1986; HILL, 2006; HYPOLITO, 2004; OZGA; LAWN, 1981 ) e como um demonstrativo da preocupação neoliberal por eficiência e produtividade que alinha oferta educacional com a economia política da 
globalização e os imperativos da competição internacional. Merson (2000, p. 160) argumenta que "[...] uma resposta para uma maior competição internacional, comum para a Nova Direita e para os modernizadores, tem sido olhar para ganhos dos trabalhadores em eficiência e produtividade. Isso tem levado à intensificação do trabalho de professores."

No Brasil, o tema dos salários do magistério e a flexibilização do trabalho são mascarados por uma representação sobre os docentes como pertencentes às classes médias. Docentes de escolas pública enfrentam uma ambivalência em relação à sua classe, uma vez que seus relacionamentos, seu local de trabalho, o lugar onde vivem, são pertencentes ao ambiente de classe trabalhadora, e mesmo assim ainda são considerados como profissionais que realizam "[...] um trabalho intelectualizado de classe média." (HYPOLTO, 2010). Como tal, os docentes podem ser percebidos como profissionais que, como qualquer outro profissional, devem desempenhar suas funções para manter um status, o que pode operar contra um apoio popular para as causas docentes. Independentemente de quão controversa esta idéia possa ser, a proletarização da profissão docente torna-se invisível ou percebida como justa no contexto da acirrada competição entre trabalhadores de classe média. De fato, 16 o conceito de desprofissionalização aplicado ao contexto brasileiro obscurece o fato de que aos professores e às professoras, historicamente, têm havido uma negação do status profissional desfrutado por outras ocupações de classe média, situação de ter o status profissional negado, não uma única vez, mas duas vezes; vamos desenvolver este argumento mais adiante. Referindo-se ao contexto brasileiro, Hypolito (2004, Introdução, $\S 2$ e 7) identifica, de forma pertinente, a "[...] profissionalização como uma terra prometida e um sonho negado $[. .]$.$" ", acrescentando que "[...] tem havido indicações visíveis de que$ este discurso tem sido usado muito mais para criar uma ilusão de que passos significativos estão sendo dados nesta direção, quando, de fato, o que tem acontecido é a criação de políticas educacionais e administrativas que servem mais para negar ao invés de afirmar práticas profissionais."

Uma outra característica da desprofissionalização e da desqualificação, em termos mundiais, pode ser vista no reducionismo e na 'racionalização' dos cursos de formação docente e na abertura para novos tipos de cursos de capacitação, menos acadêmicos e mais flexíveis; por exemplo, 'Teach for America' nos EUA, 'TeachFirst' na Inglaterra, e mais recentemente "Teach for All', que está apoiando iniciativas no Brasil, Chile, Argentina, Israel, Líbano, 
China, Alemanha, Estônia, Letônia, Lituânia, Bulgária e Austrália. (BALL; JUNEMANN, 2011 ; KINCHELOE, 2009). Essas iniciativas removem muito do conteúdo teórico e crítico da formação docente e visam colocar estudantes recém graduados, os mais bem qualificados, em salas de aula de escolas "desafiadoras" após poucas semanas de treinamento para um compromisso de dois anos. São iniciativas basicamente financiadas por corporações filantrópicas, embora possam ser também subsidiadas com verba pública, e são o exemplo do aumento da presença do setor privado como peça chave, globalmente falando, para as políticas educacionais e para a prestação de serviços; a Fundação Bill e Melinda Gates é uma dentre inúmeras organizações filantrópicas que, por exemplo, financiam Teach For America, e na Inglaterra vários bancos comerciais e de investimentos, tais como HSBC e Goldman Sachs, também estão muito envolvidos'.

Em um detalhado estudo que enfatiza sérios problemas com a efetividade das práticas de ensino promovidas pelo 'Teach for America' (TFA), Heilig e Jez (2010, p. 1) observam que "TFA não é um programa de formação docente tradicional. Ao invés daextensa preparação que os educadores tradicionalmente recebem em uma formação de quatro anos "[...] os inscritos no Teach for America assistem a um programa de treinamento de cinco semanas no verão, entre o período de sua formatura e o início de suas novas atividades de ensino." Embora a retórica governamental mundo afora constantemente afirme a importância de professores bem formados e qualificados, seus entusiásticos apoios a programas como esses soam muito contraditórios.

\section{Flexibilização}

O neoliberalismo global dirige-se para a flexibilização, na qual se pode identificar vários elementos que contribuem para a desprofissionalização docente, e que estão assentados numa relação antagônica com o profissionalismo tradicional. Inicialmente, há a desregulação do trabalho docente, com o concomitante crescimento de vários trabalhadores não docentes com baixos salários assumindo responsabilidades em salas de aula. Na Inglaterra², por exemplo, desde a década passada tem havido um grande aumento no número de assistentes de ensino nas escolas, com leis relativas ao trabalho muito flexíveis para a contratação de pessoal. Isso está articulado com as políticas 
governamentais como forma de liberar o tempo dos professores por meio da transferência de atividades não essenciais para esse pessoal de apoio. Stevenson (2007, p. 235), entretanto, observa que "[...] em algumas áreas, tais como aquelas relativas à burocracia e à administração, há alguma disputa sobre o que seja atividade não essencial. Portanto, o que está enviesado é que tarefas não-essenciais envolverão muitos aspectos do trabalho docente, cruciais para as tarefas centrais do ensino, incluindo planejamento, transmissão e avaliação de conteúdos para classes inteiras de estudantes." Classificações ambíguas de tarefas não-essenciais resultam em uma tendência à baixa remuneração, a pessoal de apoio e assistência com formação menos qualificada para empreender importantes trabalhos anteriormente atribuídos à jurisdição profissional docente, por vezes referentes a qualificações múltiplas, com o efeito de desgastar a autoridade e o profissionalismo docente. Isso também pode ser compreendido como um processo de fragmentação, em que a (re)distribuição de tarefas, práticas e equipe resulta, em alguns casos, na redefinição de aspectos do trabalho docente como não profissionais, o que tem o efeito de corroer o conhecimento unitário das práticas de ensino, o que coloca os professores como intercambiáveis e descartáveis.

18 A flexibilização pode igualmente ser vista como a subordinação docente ao pagamento por desempenho, o que é parte de um processo de individualização da privatização e mercadorização em que os professores são postos em relações competitivas uns com os outros - como já observado acima - e contribui para a desagregação do poder político e coletivo da profissão docente e de seus sindicatos. (KESSLER; PURCELL, 1991). Esse processo tem um efeito de desprofissionalização à medida que a progressão na carreira e o aumento de salários "[...] estão amarrados ao alcance de resultados padronizados orientados de forma centralizada, [os quais são] indiscutivelmente um dispositivo para aumentar o controle gerencial." (FORRESTER, 201 1, p. 7). Este é um fenômeno global, com pagamento de professores por desempenho implantados em vários países, tais como EUA, Nova Zelândia, Israel, Hong Kong, Japão e Austrália. (BALL, 2008; BELL; STEVENSON, 2006). A construção da substituição e da performatividade também estabelece as bases para um deslocamento radical da provisão do setor público por contratos e o envolvimento de fornecedores para novos lucros (como tem sido visto na Espanha, Chile e Suécia). 


\section{Centralização}

Além de tornar a escolarização mais suscetível ao crescimento econômico e à mudança social, outro conjunto de tendências e inclinações tem aparecido nas últimas três décadas e de alguma forma modifica a natureza do trabalho docente e do profissionalismo. Cada vez mais, os políticos e os formuladores de políticas produzem de forma mais direta modos de regulação para controlar o trabalho docente e mudar suas condições de emprego lembora este tenha sido o caso de sistemas historicamente centralizados - França, Europa do Leste, Finlândia etc.). Com esta finalidade, docentes e seus sindicatos estão sob pressão da mercadorização e de um controle mais rigoroso por intermédio de currículos centralizados e exames nacionais. (APPLE, 2006). Como Dale (1989) lucidamente conceitua, o que ocorre é um movimento da autonomia licenciada à autonomia regulada.

Sob a autonomia licenciada, havia "[...] uma licença implícita garantida pelo sistema educacional, a qual era renovável sob certas condições... sujeita a certas limitações gerais." (DALE, 1989, p. 130). Sob tais circunstâncias, o professorado tinha, até certo ponto, uma liberdade relativa para decidir não só como ensinar mas também o que ensinar. "Tinha uma responsabilidade particular sobre o desenvolvimento curricular e a inovação [...]" considerando que o estado "[...] não intervinha ativamente no conteúdo nem da formação docente nem do trabalho dos docentes nas escolas." (WHITTY, 2005, p. 3). Para a autonomia regulada há uma mudança em direção a um controle mais rígido sobre os sistemas de ensino e um aumento da responsabilização docente "[...] em grande medida, por meio da codificação de monitoramento de processos e práticas anteriormente decididos pelo julgamento profissional dos professores." (WHITTY, 2005, p. 6).

Há, por exemplo, evidências mundiais de imposição de um foco na aprendizagem dos estudantes voltada para "habilidades e competências" que são chave para uma empregabilidade estreita, considerada adequada pelos empregadores de trabalhos de médio e baixo nível. (HATCHER, 2011 , p. 25). Isso pode ser observado em políticas governamentais que enfatizam a importância das habilidades básicas de alfabetização e matemática, o que tem sido o objetivo central de inúmeras English Academies ${ }^{3}$ e de Escolas Charter, nos EUA, em áreas consideradas socialmente carentes. Isso igualmente reflete o 
alinhamento crescente da educação à economia e ao requisitos do 'mundo do trabalho'.

Na medida em que os governos nacionais especificam o que é esperado que docentes e estudantes atinjam, assumem um papel mais afirmativo de intervenção no detalhado processo de ensinar, "[...] em vez de deixar tais decisões para julgamento profissional." (WHITTY, 2005, p. 6). Inserir especificamente o fechamento gradual de espaços para o julgamento e a reflexão profissional corrói a ética do profissionalismo 'licenciado', no qual a profissão de ensinar tinha a garantia de "[...] uma medida de confiança e autonomia, salários profissionais e garantias ocupacionais, além de respeito e dignidade profissional." (GRACE, 1987, p. 221).

Processos de centralização e 'decentralização' tornam-se mais complexos à medida em que se atente às mudanças ontológicas, tanto na forma e modalidade do Estado quanto nas formas em que ele governa. Como exemplo alguns teóricos chamam a atenção para a crescente mudança do uso do termo governo para governança, ou o uso do termo 'governando por rede'. (EGGERS, 2008). Essa forma de governança funciona por meio da interdependência, parceria e colaboração entre inúmeros atores estatais e não estatais, 20 públicos/privados e lucrativos/sem fins lucrativos no desenvolvimento e difusão de políticas públicas e sociais. Nesse sentido, governos estão crescentemente posicionados como facilitadores na "[...] catalização de todos os setores - público, privado e voluntário - em ação para solucionar seus problemas comunitários." (OSBORNE; GAEBLER, 1992, p. 20). É o que Jessop (2001) descreve como o 'estado policêntrico'. Há áreas em que o estado renuncia ao seu poder e responsabilidade, contudo "[...] essas mudanças na modalidade não indicam um enfraquecimento profundo da capacidade do estado em dirigir as políticas, embora internacionalmente isso possa variar de nação para nação. O estado é vigoroso nesses processos de governança." (BALL, 2009, p. 96). Sem dúvida, Jessop (2002, p. 199 apud BALL, 2009) sugere que o estado aumenta sua "[...] capacidade para projetar sua influência e garante seus objetivos mobilizando recursos de poder e conhecimento de influentes grupos de interesse e parceiros não governamentais." Nessas mudanças de governança há reciprocidade entre as exigências do capital e do estado, na medida em que os processos de privatização oferecem oportunidades para a acumulação de capital, no que se refere às empresas, e reduções nos gastos públicos para os governos. Ball (2009, p. 97) indica que "[...] há condicionamento e 
acomodação mútuos [...]. O estado funciona para desenvolver meta-capacidades e apoia o desenvolvimento de 'novas narrativas políticas' que por sua vez mobilizam apoio para a expansão das oportunidades empresariais."

\section{Performatividade}

Flexibilização e centralização estão relacionadas com e habilitadas pelas técnicas de performatividade e gestão de desempenho. De acordo com Ball, performatividade é "[...] uma cultura ou um sistema de 'terror [...]'" em que "docentes, pesquisadores e acadêmicos estão sujeitos a uma miríade de julgamentos, medidas, comparações e metas." (BALL, 2008, p. 49-50). Sua principal característica é o crescente uso de compilação de dados, revisões anuais, publicação de resultados de aprendizagem, inspeções e relatórios escritos. Muitos trabalhos acadêmicos têm documentado os impactos das políticas performáticas sobre o trabalho e a vida profissional de docentes, assim como seus sentimentos e identidades de trabalho (ver, por exemplo, MAHONY, HEXTALL;,MENTER, 2002; 2004; 2004; PERRYMAN, 2007; 2009; WOODS; JEFFREY, 2002). Novas linguagens incorporadas nessas políticas, tais como desempenho, competências, padronização e responsabilização, são capazes de constituir novos modos de pensar sobre o que os professores fazem. Além disso, essas novas linguagens e procedimentos redefinem a natureza das atividades de ensino e conduzem a novos modos de identificar o que vale como ser profissional. No centro dessa transformação, o ensino é retrabalhado com a instalação de uma nova cultura de performatividade.

Performatividade é uma das maiores forças das reformas educacionais contemporâneas e substancialmente modifica a estrutura do dia a dia do fazer das escolas e do ensino; além disso, é um "novo modo de regulação do estado" (BALL, 2003), o que torna possível 'formar' novos professores e reorientar o que significa ser um professor. Performatividade também tem um impacto direto sobre as experiências emocionais dos docentes, com sentimentos de vergonha, culpa, orgulho e inveja, que são parte integral da efetividade de suas várias tecnologias, em alguns casos em detrimento da saúde e do bem-estar docente. Retornaremos ao impacto dessas políticas sobre a subjetividade docente na seção final deste artigo. 


\section{Privatização exógena}

Até o momento temos tentado assinalar como a privatização endógena funciona para produzir novos sentimentos, incentivos e lógicas para os professores. Esses processos demonstram que há efeitos negativos para o profissionalismo docente em termos de perda de autonomia e autoridade, intensificação do trabalho, desqualificação e o rompimento das negociações coletivas pela individuação. Existe, contudo, outra forma de privatização acontecendo nos sistemas de educação pública em todo o mundo que abre, de modo marcante, oportunidades para o lucro. Esta forma de privatização pode ser denominada 'exógena', já que "[...] envolve a abertura dos serviços da educação pública para a participação do setor privado em bases lucrativas e utilizando o setor privado para planejar, gerenciar ou fornecer partes da educação pública." (BALL; YOUDELL, 2008, p. 10). Não obstante, há uma 'lógica' que relaciona privatização endógena e exógena, por meio da qual os movimentos e mudanças incorporados na primeira facilitam a última.

Globalmente, há inúmeros exemplos de privatização exógena na educação, alguns sutis e ocultos, e outros mais explícitos. Os exemplos vão

22 desde a contratação de serviços que usualmente seriam de responsabilidade dos órgãos de educação (locais/municipais) até a contratação de setores privados para a gestão escolar para perspectivas internacionais (ver Ball e Youdell, 2008); para exemplos nos Estados Unidos da América (ver Molnar e Garcia, 2007). Igualmente tem havido uma proliferação de 'edubusinesses', muitos com alcance global, juntamente com o envolvimento de corporações multinacionais que exploram as oportunidades trazidas pela privatização e mercantilização da educação e da política educacional, com a venda de serviços educacionais e soluções políticas que constituem um mercado crescente e lucrativo. Isso se estende aos recursos didáticos e equipamentos escolares, incluindo a produção e venda de livros didáticos e materiais de ensino e aprendizagem. No Brasil, por exemplo, isso pode ser visto de forma crescente, nos últimos anos, com a distribuição de materiais e livros didáticos, especialmente dentre as escolas municipais, que são desenvolvidos e produzidos por empresas privadas (ver, por exemplo, Adrião, Garcia, Borghi, Arelaro, 2009). Este mercado não é somente lucrativo; também abre as escolas e as práticas de ensino e aprendizagem para a influência do setor privado. Igualmente, e apenas como um exemplo, no Reino Unido o banco comercial e de investimento 
HSBC tem-se envolvido com desenvolvimento curricular por meio do programa chamado 'O que dinheiro significa', o qual tem sido testado e experimentado em inúmeras escolas primárias ${ }^{4}$. Esta iniciativa não só envolve a venda de recursos de ensino e aprendizagem para as escolas, docentes e pais, assim como a produção de estudantes e, sem dúvida, docentes, como competentes 'sujeitos financeiros'. Em um sentido mais amplo, este tipo de atividade é mais um exemplo de complexas, mas crescentemente prevalentes interações e relacionamentos entre filantropia, capital e empreendimento social na influência, produção e valorização da política e da oferta em educação. Para os propósitos deste artigo, o foco será dado no envolvimento direto do setor privado na gestão de escolas, e, em particular, nas liberdades legais e institucionais muito apreciadas pelos 'novos' provedores de educação pública, que é muitas vezes referido como liberalização da oferta. (DEPARTMENT FOR EDUCATION, 2012; HATCHER, 20111 .

Suécia e Chile possuem, sem dúvida, o sistema escolar de mercado mais avançado do mundo, anteriormente financiado com fundos públicos, as 'escolas livres' de propriedade privada agora se encontram bem entrincheiradas no sistema escolar público e geram, em alguns casos, lucros substanciais (ARREMAN; HOLM, 2011 ; FREDRIKSSON, 2009) com o posterior sistema de vales (voucher), com os quais os pais podem custear tanto escolas municipais ou 'privadas'. Nos EUA há um número crescente de escolas charter administradas por Education Management Organisations (Organizações de Gestão Educacional). A desprofissionalização é muito significativa no contexto de emergência desses 'novos' provedores, dado que tais tipos de escolas possuem maior flexibilidade sobre o pessoal que empregam, os salários que pagam e as condições sob as quais o trabalho é realizado. Em alguns casos, esse tipo de escola possui maior autonomia sobre o conteúdo do currículo e os modos de distribuição curricular. Uma vez que os provedores estejam aptos a lucrar, como é o caso na Suécia e nos EUA, dentre outros, o maior obstáculo que surge é com os custos de pessoal. Comentando sobre as escolas charter nos EUA, Molnar e Garcia (2007, p. 17) observam que "[...] o modo mais simples para reduzir custos com pessoal é reduzir a remuneração dos professores, o que é mais facilmente obtido com a contratação de professores com menos experiência e menor qualificação ou contratar menos professores e aumentar o tamanho das turmas." Ocorre aqui tanto uma lógica de desqualificação como de intensificação, com professores inexperientes ou não qualificados sendo contratados para trabalhar, em alguns casos, com turmas maiores. 
No caso dos EUA tem sido estimado que "[...] aproximadamente 70-80\% dos orçamentos escolares é para pessoal: salários e benefícios de professores e administradores. Assim, a estratégia mais óbvia para buscar um lucro é reduzir os custos com pessoal." (MOLNAR; GARCIA, 2007, p. 17). Na Suécia, tais estratégias para reduzir custos tem resultado em uma grande proporção de aumento da contratação de professores não qualificados. Lundahl (201 1, p. 38) afirma que 'a proporção de docentes com curso de formação de professores é consideravelmente mais baixa nas escolas obrigatórias independentes $(67 \%)$ do que nas escolas públicas (87\%), e a taxa média professor/ aluno é menor'. No mesmo sentido, com referência às escolas Kunskapsskolan, com fins lucrativos, na Suécia, um artigo publicado no "The Economist5 , um tanto acrítico, mas revelador, compara sua organização e modo de operação - faça você mesmo - com a companhia de móveis IKEA: 'Como IKEA [...] Kunskapsskolan faz seus clientes fazerem o trabalho por eles mesmos. A ferramenta vital, porém, não é uma ferramenta allen mas a Kunskapsporten (portal do conhecimento), um website que contém todo o plano de ensino." (2008). Este exemplo extremo destaca o aumento da subvalorização do ensino e dos professores. Isso sugere que para esses novos provedores, a contratação do 24 "barato", 'docentes desqualificados, juntamente com formas tecnologizadas de pedagogia, constitui uma parte dos seus planos de negóció.

Antes de mudar o tema para a discussão sobre o impacto dessas políticas e das reformas neoliberais sobre a subjetividade docente, é importante apontar que o processo dual de privatização endógena e exógena que descrevemos são ditadas de modo diferente em diferentes contextos. Por exemplo, as reformas educacionais na Inglaterra decretaram um processo gradual e inicial de privatização endógena que preparava, de certo modo, a base para um envolvimento subsequente do setor privado com a privatização exógena. Esta forma de imposição, contudo, não tem sido vista nas reformas educacionais de outros países. Como exemplo, o Chile tem tido um forte envolvimento do setor privado na provisão de serviços educacionais há vários anos. De certo modo, a privatização exógena esteve em primeiro lugar, com as reformas neoliberais subsequentes determinando o tipo de privatizações endógenas, acima detaIhadas, na forma de Nova Gestão Pública. Esta comparação indica os modos como especificidades e histórias locais e nacionais modulam as formas como as reformas neoliberais são implementadas e materializadas. 


\section{Discursos políticos e subjetividades docentes}

Políticas não podem ser entendidas somente como textos, para se compreender como elas constituem as subjetividades docentes, precisam ser entendidas como discursos. Discursos políticos "[...] produzem quadros de sentido e obviedade com os quais a política é pensada, falada e escrita. Textos políticos são definidos no interior desse quadro que constrange mas nunca determina todas as possibilidades de ação." (BALL, 2006, p. 44). Se consideramos políticas como discursos, então temos que olhar para elas não somente como "[...] pré-eminentemente, declarações sobre a prática - o modo como as coisas poderiam ou deveriam ser - donde se baseiam, derivam, declarações sobre o mundo - sobre o modo como as coisas são" (BALL, 2006, p. 26), mas também como práticas em si mesmas, "[...] práticas que formam sistematicamente os objetos de que falam [...]. Discursos não são sobre objetos; não identificam objetos, os constituem e na prática de os constituir ocultam sua própria invenção." (FOUCAULT, 2002, p. 49).

Inicialmente, o discurso neoliberal significou a redução do estado a fim de permitir o desenvolvimento de um mercado sem restrições; contudo, o papel do estado tem sido redefinido como um aliado do mercado, para definir as condições adequadas para que o mercado possa operar. Para que isso ocorra,

[...] os objetivos finais de liberdade, escolha, soberania do consumidor, competição e iniciativa individual, assim como aqueles de cumprimento e obediência, devem ser construções do estado agindo agora em seu papel positivo por meio do desenvolvimento de técnicas de auditoria, prestação de contas e gestão. (OLSSEN; PETERS, 2005, p. 315).

Este "papel positivo" do estado também tem implicações para o comportamento individual, pois o estado "[...] procura criar um indivíduo que é um empresário empreendedor e competitivo." (OLSSEN, 1996, p. 340). Assim, conforme descrição anterior neste texto, um discurso de mercado tem ido muito além do setor comercial, penetrando no setor público de várias formas.

Ball afirma que "[...] a aplicação do modelo de mercado para as instituições do setor público engloba, requer e legitima uma variedade de mudanças que são estruturais e processuais, mas que também trazem à cena 
novos valores e novos tipos de relações sociais." (BALL, 2006, p. 115). 0 discurso neoliberal, assim, reconfigura a relação entre o estado e o indivíduo, uma vez que "[...] apresenta as forças do mercado como uma oferta a todos, com chances iguais para utilizar seu poder de escolha e controle como consumidor. Aqueles que não exploram suas oportunidades, tem apenas a si mesmos para culpar." (VINCENT, 1994, p. 263).

De Lauretis (1986, p. 5) define subjetividade como os "[...] padrões pelos quais contextos vivenciais e emocionais, sentimentos, imagens e memórias são organizados para formar a própria imagem, o sentido de si e dos outros, e as nossas possibilidades de existência." Pensar a subjetividade docente implica em ver que os discursos políticos neoliberais modificam o modo como os professores pensam a si mesmos e o seu trabalho, o que significa ser professor, o que é ensinar. Modifica as relações entre os colegas, estudantes e líderes. Constitui a própria educação em novas formas - como desempenho/ performance e como mercadoria. É o que se realiza nas práticas, nas relações e nas subjetividades. É importante ressaltar que o neoliberalismo não é apenas algo 'por aí' em novas estruturas, procedimentos e 'liberdades', está 'aqui' em nossas cabeças, estamos neoliberalizados!

26 A ênfase na competição e no desempenho tem alterado a natureza do que os professores e as professoras fazem e como veem a si mesmos como docente. Estão agora alinhados mais com a lógica, os valores e a ética do imperativo econômico. Definições regulares de metas, sistemas de avaliação e comparações de desempenho atuam como técnicas reguladoras que designam novas posições de sujeito para os professores. Consequentemente, novos papéis e subjetividades são produzidos nesta cultura de performatividade. Os docentes não são apenas "[...] conduzidos e encorajados a pensar sobre si mesmos como indivíduos que calculam a si mesmos, acrescentam valor a si mesmos, melhoram sua produtividade, buscam a excelência e vivem uma existência de cálculo [...]", ao mesmo tempo são re-trabalhados como "[...] produtores/fornecedores, empreendedores e gestores educacionais." (BALL, 2003, p. $217-218$ ). Discursos políticos baseados em standards e accountability procuram reduzir o ensino a um empreendimento técnico baseado em um conjunto de competências e habilidades em vez de práticas bem informadas por princípios éticos. $O$ discernimento para tomar decisões éticas no processo de ensino e aprendizagem é corroído e deslocado por exigências de performatividade, automedições e marketing. $\bigcirc$ profissional docente é 
assim reconstituído como alguém que pode "[...] transmitir eficientemente de acordo com a contratação de um serviço de cliente, em conformidade com procedimentos de prestação de contas colaborativamente implementados e gerencialmente assegurados." (HOYLE, 1995, p. 60). Sob esta nova versão de profissionalismo, contudo, os profissionais docentes não apenas "[...] são mais ativamente administrados [...]", mas "[...] estão muito mais envolvidos em tarefas de gestão autorreguladoras [...]", tais como estabelecimento de metas, monitoramento e avaliação. (GLEESON; GUNTER, 2001, p. 146). Por conta disso, a inculcação de capacidades de autorregulação e autovigilância é às custas da perda de códigos éticos autônomos do que vem a ser um profissional docente. Paradoxalmente, os docentes tornam-se novos seres "autônomos" com propensão a fazer-se sempre disponível e administrável para os discursos políticos de desempenho e mercado, estão inseridos em um projeto que é passível de ser desenvolvido, melhorado e sujeito à regulação.

\section{Conclusão}

No contexto global da economia do conhecimento a educação é a arena de crescentes e diversificadas lutas políicas. Para se entender essas lutas, é importante avaliar tanto a natureza global e o poder dos discursos políticos em redefinir as práticas, os fins e valores da educação, assim como reconstituir a subjetividade docente. Como produtos situados em um contexto, as políiticas articulam significados e recursos materiais em um determinado ponto no espaço e no tempo. Nesse sentido, uma abordagem crítica para a análise de políticas objetiva "desnaturalizar" os fundamentos, assunções e ordens implícitas que uma políica envolve. Para esse fim, é preciso examinar como uma política está ancorada em condições históricas locais, quais suas interconexões ou relações com outros dispositivos políiticos e, por último, mas não menos importante, como está ancorada no desenvolvimento das tendências globais, as quais constituem o foco deste artigo.

O que tentamos mostrar são algumas das semelhanças e dos efeitos típicos das reformas educativas neoliberais e globais, e ao mesmo tempo enfatizar a importância de dar mais atenção aos modos como essas reformas são materializadas e decretadas em contextos locais específicos. Ao fazer isso, 
estamos caminhando na "linha tênue" que Peck e Tickell (2002) descrevem como algo que produz,

[...] por um lado, narrativas super generalizadas de um neoliberalismo monolítico e onipresente, que tende a ser insuficientemente sensível para sua variabilidade e constituição interna complexa e, por outro, análises excessivamente concretas e contingentes das estratégias neoliberais (locais), as quais são inadequadamente atentas às conexões substanciais e às características necessárias do neoliberalismo como um projeto extra local. (PECK; TICKELL, 2002, p. $381-3821$.

Ao mesmo tempo em que tentamos oferecer alguns exemplos da natureza variável das imposições das reformas educativas neoliberais locais em diferentes países ao redor do mundo, tentamos situá-los em uma "visão global" atenta "[...] às características mais gerais e abstratas do processo de neoliberalização." (PECK; TICKELL, 2002, p. 382).

As recentes reformas educativas no Brasil, a que nos referimos, certamente refletem muitas, mas não todas, das características "genéricas" e "abstratas" da neoliberalização global da educação. Uma variação contextual significativa, nesse sentido, é que as lutas por profissionalismo docente no Brasil são talvez mais agudas naquilo que as reformas neoliberais estabelecem em um contexto educacional que tem historicamente negado aos docentes um status profissional. Retornando à importante observação de Hypolito (2004), o que é evidente é que os docentes no Brasil tiveram negada, não apenas uma, mas duas vezes, a terra prometida da autoridade e da autonomia profissional que foi outrora desfrutada, em alguns aspectos cruciais, pelos docentes em outros países. Em vez de um processo redutivo de desprofissionalização, os professores e as professoras no Brasil estão sendo constrangidos a uma estagnação pré-profissional, com o redesenho neoliberal das suas práticas e condições de trabalho que atuam para minar, desvalorizar e explorar o seu trabalho. Compreender como o conjunto particular de políticas neoliberais no Brasil constitui a subjetividade docente é um processo contínuo de interpretação. Desejamos que este artigo seja útil para destacar algumas das dimensões que explicam o poder real das políticas que avançam e como estão relacionadas entre si. 


\section{Notas}

1 Esses esquemas são fortemente patrocinados e apoiados pelas corporações e pela filantropia privada, todavia as organizações e companhias aqui mencionadas são somente uma pequena parte de uma gama de patrocinadores. Teach For All, como esquema global, é uma versão articulada do Teach For America e do TeachFirst [Ensina! Brasil, versão brasileira dessas iniciativas]. Teach for All descreve-se como "[...] uma rede global de empreendedores sociais trabalhando para expandir as oportunidades educacionais em seus países [...] sua missão é expandir internacionalmente as oportunidades educacionais aumentando e acelerando o impacto desses empreendimentos sociais." (TEACH FOR ALL, 2012). Esses modelos reduzem a complexidade das questões sociais pelo seu impacto sobre a desigualdade educacional, e propagam as ideologias neoliberais próprias das tão conhecidas virtudes humanas "naturais" de "responsabilidade pessoal", "autossuficiência" e "empreendedorismo", em que "[...] no modelo neoliberal, a responsabilidade pela autorrealização... é depositada no individual." (HEARN, 2008, p. 203).

2 A Inglaterra possui indiscutivelmente o sistema educativo mais neoliberal dentre os quatro que existem na Grã-Bretanha.

3 English Academy no sistema educativo na Inglaterra é um tipo de escola independente da autoridade educacional local, mas possui financiamento público, podendo possuir algum tipo de patrocinador privado. Pode ser grosseiramente comparada com as Charter Schools nos EUA. Foram criadas no ano de 2000 e modificadas na Lei de Educação de 2002. [N.T.]

4 Este é um programa de parceria entre PersonalFinanceEducationGroup, um empreendimento social, e o banco HSBC. O programa é descrito como "um programa de cinco anos para aumentar a quantidade e a qualidade da educação de finança pessoal nas escolas primárias. Por meio de um trabalho direto com docentes e crianças, What Money Means tem conseguido criar uma riqueza de recursos que tem sido experimentado com sucesso e rigorosamente testado nas escolas na Inglaterra" (PersonalFinanceEducationGroup, 2012).

5 The Economist é uma publicação de assuntos internacionais, sediada no Reino Unido, que assume uma posição pelo 'livre mercado'.

6 Deve ser igualmente observado que tais escolas muitas vezes estão situadas em prédios não planejados para propósitos educacionais, como conjuntos para escritórios e prédios de armazéns. Companhias, tipo Kunskapsskolan, dentre outras tais como Jon Bauer, também alugam prédios para reduzir custos com a alegação da necessidade de reduzir despesas de manutenção.

\section{Referências}

ADRIÃO, T., GARCIA, T., BORGHI, R.,ARELARO, L. Uma modalidade peculiar de privatização da educação pública: a aquisição de "sistemas de ensino" por municípios paulistas. Educação \& Sociedade, Campinas, v. 30, n. 108, p. 799-8 18, 2009.

APPLE, M. W. Education and power. Boston: Routledge \& Kegan Paul, 1982. 
Teachers and texts: a political economy of class and gender relations in education. London: Routledge \& Kegan Paul, 1986. Markets, standards, teaching, and teacher education. Journal of Teacher Education v. 52, n. 3, p. 182-196, 2001. Understanding and interrupting neoliberalism and neoconservatism in education. Pedagogies, v. 1, p.21-26, 2006.

Creating difference: neo-liberalism, neo-conservatism and the politics of educational reform. Educational Policy, v. 18, n. 1, p. 12-44, 2004.

ARREMAN, I. E.; HOLM, A. S. Privatisation of public education? The emergence of independent upper secondary schools in Sweden. Journal of Education Policy, v. 26, n. 2, p. 225-243, 2011.

BALL, S.; YOUDELL, D. Hidden privatisation in public education. 2007.

BALL, S. J. The teacher's soul and the terrors of performativity'. Journal of Education Policy, v. 18, n. 2, p. 215-228, 2003.

Education policy and social class. The selected works of Stephen J. Ball. New York: 30 Routledge, 2006.

The education debate: the policy press. 2008.

Privatising education, privatising education policy, privatising educational research: network governance and the 'competition state'. Journal of Education Policy, v. 24, n. 1, p. 83-99, 2009.

BALL, S. J.; JUNEMANN, C. Network governance and coalition education policy. In: R. Hatcher and K. Jones (Eds). No country for the Young. London: Tufnell Press, 2011.

BALL, S. J.; YOUDELL, D. Hidden privatisation in public education: Education International Brussels, 2008.

BELL, L.; STEVENSON, H. Education policy:process, themes and impact: Taylor \& Francis, 2006.

DALE, R. The state and education policy: Open University Press Milton Keynes, 1989.

DELAURETIS, T. Feminist studies, critical studies: Indiana University Press, 1986. 
EGGERS, W. The changing nature of government: network governance. In: J. O'Flynn and J. Wanna (Eds). Collaborative governance: a new era of public policy in Australia? Canberra: ANU E Press, 2008.

FELDFEBER, M. La regulación de laformación y eltrabajo docente: unanálisiscritic de la "agenda educativa" en América Latina. Educação \& Sociedade, Campinas, v. 28, n. 99, p. 444-465, 2007.

FORRESTER, G. Performance management in education: milestone or millstone? Management in Education, v. 25, n. 1, p. 5-9, 2011.

FOUCAULT, M. Archaeology of knowledge. London/New York: Routledge, 2002.

FREDRIKSSON, A. On the Consequences of themarketisation of public education in Sweden: for-profit charter schools and the emergence of the'market-oriented teacher'. European Educational Research Journal, v. 8, n. 2, 2009.

GENTILI, P.; SUAREZ, D.; STUBRIN, F., GINDIN, J. Reformaeducativa y luchasdocentes en América Latina. Educação \& Sociedade, Campinas,v. 25, n. 89, p. 125 1-1274, 2004.

GLEESON, D.; GUNTER, H. Managing 'performance' in the performing school. In: C. Husbands and D. Gleeson (Eds). The performing school: managing, teaching and learning in a performance culture.2001. (p. 7-19).

GRACE, G. Teacher and the State in Britain. In: M. Lawn and G. Grace (Eds). Teachers: the culture and politics of work. London: Falmer, 1987. (p. 239).

HARGREAVES, A. Changing teachers, changing times: teachers' workand culture in the postmodern age. London: Cassell, 1994.

HATCHER, R. Liberating the supply side, managing the market. In: R. Hatcher and K. Jones (Eds). No country for the Young. London: Tufnell Press, 2011.

HEARN, A. 'Meat, Mask, Burden': probing the contours of the branded 'self'. Journal of Consumer Culture, v. 8, n. 2, p. 197-217, 2008.

HEILIG, J. V. J. S. J. Teach for America: a review of the evidence. Boulder and tempe: Education and the Public Interest Center \& Education Policy Research Unit, 2010.

HILL, D. Class, capital and education in this neoliberal/neoconservative period. Information for Social Change, v. 23, p. 1 1-35, 2006.

HOYLE, E. Changing concepts of a profession. In: H. Busher and R. Saran (Eds). Managing teachers as pofessionals in shools. London: Kogan Page, 1995. (p. 209). 
HYPOLITO, A. M. Teachers' work and professionalization: the promised land or dream denied. Journal for CriticalEducation Policy Studies, v. 2, n. 2, 2004.

Políticas curriculares, Estado e regulação. Educação \& Sociedade, Campinas, v. 31 , n. 113, p. 1337-1354, out-dez. 2010.

JESSOP, B. Bringing the state back in (yet again): reviews, revisions, rejections, and redirections. International Review of Sociology, v. 1 1, n. 2, p. 149-173, 2001.

The future of the capitalist state. Cambridge: Polity, 2002.

KESSLER, I.;PURCELL, J. Performance related pay: theory and practice, presented at the 1Oth Colloquium for the European Group of Organisation Studies. Vienna, 1991.

KINCHELOE, J. Contextualizing the madness: a critical analysis of the assault on teacher education and schools. In: GROENKE S. L.; Hatch J. A. (Eds.). Critical pedagogy and teacher education in the neoliberal era: Small Openings: Springer, 2009.

LARNER, W. Neo-liberalism: policy, ideology. Governmentality. Studies in Political Economy, v. 63, 5-25, 2000. (Autumn).

LARSON, M. S. Proletarianization and educated labor. Theory and Society, v. 9, n. 1, p. $32 \quad 131-175,1980$.

LUNDAHL, L. The emergence of a Swedish school market. In: Hatcher, R.; JONES, K. (Eds). No country for the Young. London: Tufnell Press, 2011.

MAHONY, P.; HEXTALL, I.; MENTER, I. Threshold Assessment: another peculiarity of the english or more McDonaldisation? International Studies in Sociology of Education, v. 12, n. 2, p. 145-168, 2002.

Threshold assessment and performance management: modernizing or masculinizing teaching in England? Gender and Education, v. 16, n. 2, p. 131-149, 2004.

The emotional impact of performance related pay on teachers in England. British Educational Research Journal, v. 30, n. 3, p. 435-456, 2004.

MERSON, M. Teachers and the myth of modernisation. British Journal of Educational Studies, v. 48, n. 2, p. 155-169, 2000.

MOLNAR, A.; GARCIA, D. R. The expanding role of privatization in education: implications for teacher education and development. Teacher Education Quarterly, v. 34, n. 2, p. 1, 2007. 
OLSSEN, M. In defense of the welfare state and publicly provided eduation. Journal of Education Policy, n. 11, p. 337-362, 1996.

OLSSEN, M.; PETERS, M. A. Neoliberalism, higher education and the knowledge economy: from the free market to knowledge capitalism. Journal of Education Policy, v. 20, n. 3, p. 313-345, 2005.

OSBORNE, D.; GAEBLER, T. Re-inventing government. Reading: Mass: Addison-Wesley, 1992.

OZGA, J. T.; LAWN, M. A. Teachers professionalism and class: a Study of Organized Teachers. London: Falmer Press Limited, 1981.

PECK, J.;TICKELL, A. Neoliberalizing space. Antipode, v. 34, n. 3, p. 380-404, 2002.

PERRYMAN, J. Inspection and emotion.Cambridge Journal of Education, v, 37, n. 2, p. 173-190, 2007.

Inspection and the fabrication of professional and performative processes. Journal of Education Policy, v. 24, n. 5, p. 611 1-631, 2009.

PERSONAL Finance Education Group What Money Means - for primary schools. [Online]. 2012. Available at: http://www.pfeg.org/our_work_in_education/what_money_means_ for_primary_schools/index.html. Lastaccessed 4th april. 2012.

SILVA, M. R.; ABREU, C. B. M. Política educativa: la reforma brasileña y sus resultados segúnelrendimiento de losestudiantes. Theomai, n. 18, (2nd semester), 2008.

SMYTH, J. Evaluation of teacher performance: Move Over Hierarchy, Here Comes Collegiality. Journal of Education Policy, v. 11, n. 2, p. 185-196, 1996.

SPRINGER, S. Neoliberalism and geography: expansions, variegations, formations. Geography Compass, v. 4, n. 8, p. 1025-1038, 2010.

STEVENSON, H. Restructuring teachers' work and trade union responses in England: bargaining for change? American Educational Research Journal, v. 44, n. 2, p. 224, 2007.

TEACH For All. 'Teach for all network'.[Online]. 2012. Available at: http://teachforall.org/ network.html. Last accessed: February, 2012.

THE ECONOMIST. Private education: the Swedish Model - A Swedish firm has worked out how to make money running free schools. [Online]. 2008. Available at: http://www. economist.com/node/1 1535645.Last accessed: 12th November. 
UNESCO. Education for All (EFA). Online. Available at: http://www.unesco.org/new/ en/education/themes/leading-the-international-agenda/education-for-all/. Last accessed: February 2012.

VINCENT, C. The market forces? The effect of local management of schools on special educational needs provision. British Educational Research Journal, v. 20, n. 3, p. 261-277, 1994.

WHITTY, G. Moving Beyond Recent Education Reform and Towards a Democratic Professionalism International. Symposium on Education Reform and Teachers Hitotsubashi University. Tokyo: Japan, 2005.

WOODS, P.; JEFFREY, B. The reconstruction of primary teachers' identities. British Journal of Sociology of Education, v. 23, n. 1, p. 89-106, 2002.

Prof. Dr. Stephen J. Ball Universidade de Londres Instituto de Educação Centro de Estudos Críticos em Políticas Educacionais E-mail | s.ball@ioe.ac.uk

Patrick Bailey | Ph. D. Student Universidade de Londres Instituto de Educação Centro de Estudos Críticos em Políticas Educacionais E-mail | pbailey@ioe.ac.uk Paula Mena | Ph. D. Student Universidade de Londres Instituto de Educação Centro de Estudos Críticos em Políticas Educacionais E-mail | pmena@ioe.ac.uk 
Pablo Del Monte | Ph. D. Student Universidade de Londres Instituto de Educação

Centro de Estudos Críticos em Políticas Educacionais E-mail | pdelmonte@ioe.ac.uk

Diego Santori | Ph. D. Student Universidade de Londres Instituto de Educação

Centro de Estudos Críticos em Políticas Educacionais E-mail | d.santori@ioe.ac.uk

Dr. Chun-ying Tseng Universidade de Londres Instituto de Educação

Centro de Estudos Críticos em Políticas Educacionais E-mail | vernalblue@hotmail.com

Helen Young | Ph. D. Student Universidade de Londres Instituto de Educação

Centro de Estudos Críticos em Políticas Educacionais E-mail | hyoung03@ioe.ac.uk

Dr. Antonio Olmedo Universidade de Londres Instituto de Educação Centro de Estudos Críticos em Políticas Educacionais E-mail | a.olmedo@ioe.ac.uk 
Recebido 11 ago. 2013

Aceito 8 out. 2013 